\title{
A tragédia contemporânea - ignorância
}

\author{
Márcio Aurélio
}

Ancient art has a specific inner content. At one time, art possessed the same purpose that books do in our day, namely: to preserve and transmit knowledge. In olden days, people did not write books, they incorporated their knowledge into works of art. We would find a great many ideas in the works of art passed down to us, if only we knew how to read them (G. Gurdjieff).

o terminar a primeira leitura de AGRESTE de Newton Moreno, devolvi o texto ao envelope e lá permaneceu por aproximadamente um ano. Como lidar com esse material? Não interessava o possível lado panfletário e folclórico que, pelo tratamento, poderia ser mal interpretado. Não restava dúvida de que é teatro da melhor qualidade, mas como processá-lo? Quais os possíveis erros que o envolvem? Não se trata de dramaturgia convencional e, sendo assim, exigiria atitude diferenciada para encará-la. Atores treinados para isso. Um dia tivemos longa conversa, o autor e eu. Era preciso esse tempo. Tempo de maturação que se fez necessário. Parceiros e cúmplices, montamos nossa estratégia.
Há um dado concreto. Como se passara todo este tempo, muita gente já conhecia o texto. Expectativas. Desejos. O texto já tinha sido lido em diversos eventos. Não quis nunca assistir a essas leituras dramáticas. $\mathrm{O}$ texto tinha determinadas chaves que me parecia importante serem descobertas em processo. Ele permaneceu lá. No envelope. Periodicamente, visitas de boa vizinhança. Chegança!

Queríamos testar diferentes possibilidades para buscar a alquimia que o trabalho pedia. Isto é precioso no teatro. Para tanto, a ansiedade deveria ser colocada no grau zero. Este é para mim o estado ideal para a escritura da poesia da cena.Tudo por fazer, mas apostando no prazer do percurso a ser vivenciado para se encontrar o melhor, sabendo-se que não se tem nada, a não ser homens e suas histórias. Não queria pensar em adornos. Escapes. Só a busca. É nela que se encontra para os homens de teatro o compromisso moral do fazer artístico. Com Apolo a possibilidade da forma ideal, com Dionísio o prazer embriagador da poesia humana provocando todos os contrastes e as contradições. Continuo acreditando que o teatro está centrado nisto como força expressiva e, dessa forma, continuamos uma tradição secular, ou

Márcio Aurélio é encenador, pesquisador e professor do Instituto de Artes da Unicamp. 
seja, a de sermos contadores de nossas próprias histórias. E, apesar de tudo, continuamos ignorantes sobre nós mesmos. $\mathrm{Na}$ poesia do teatro temos todo o conhecimento e nossa ignorância. Preconceito. A peça mostra isso. Ignorantes.

\section{Razões inversas}

A Companhia Razões Inversas, desde a sua criação, tem procurado manter um trabalho tendo como objetivo a montagem de grandes textos da dramaturgia. Por grandes textos não pensamos em textos consagrados, mas em textos em que se possa reconhecer questôes importantes para a reflexão sobre transformação social do homem. Mais interessante ainda é se pudermos relativizar e contextualizar os temas e identificar as questóes, ou seja, como e onde o homem se encontra nos diferentes relatos poéticos da história.

Foi assim com Shakespeare, que tomamos por três vezes para refletir sobre a reorganização e o desmoronamento do sonho da sociedade brasileira com o antes, o durante e o depois do impeachment de Fernando Collor; com Kleist para servir de pano de fundo da risível mudança e implantação da nova constituição em nosso país; com Müller na tentativa de recompor o sentido poético da intimidade, da lírica, em uma sociedade que se destrói; com Goethe e Brecht para pensar a crise do artista e seu papel como organizador da poesia de seu tempo diante do estado; com Schznitsler, o desmoronamento e a desolação moral burguesa diante do desejo; com De Filipo, o descrédito do Estado para com o artista cênico e sua atuação social.

Agora, depois de anos de criações e realizaçōes, nos deparávamos com uma situação insustentável pela ausência de possibilidades para continuidade de nosso trabalho, tanto pelo fator econômico como artístico, diante de um quadro extremamente complexo. E dentro dessa condição resolvemos dar mais um passo. Essa era a nossa realidade. Mas, como todo artista traz consigo o estigma do mito de Sísifo, reini- ciamos mais uma vez nosso projeto. Consistia em retomar algumas experiências e estudar a idéia de teatro narrativo e a possibilidade de construção de uma cena pós-dramática, contemporânea, indo além das realizações anteriores. Assim sendo, retomamos o trabalho já realizado sobre Schopenhauer e seu diálogo com Shakespeare, Dostoievski e Ovídio, entre outros tantos, na busca de material que nos projetasse à frente. Linguagens poéticas que proporcionassem estímulos para buscar um diálogo contemporâneo com o público, redimensionando mitologias que pudessem gerar avanços e questionamentos. Pensávamos, entretanto, que tudo isso não devia perder de vista o homem urbano e suas questôes. Não conseguíamos focar verdadeiramente o ponto temático sobre o qual nos debruçarmos. Em avaliaçôes anteriores de nosso trabalho já tínhamos chegado à conclusão de que a forma é mera decorrência do processo: o importante é o que dizer. E para quem! E porque. Nisso concordo com Giorgio Tabori quando reflete que o teatro é o último espaço do humanismo. Pura representação do jogo social.

Um dia sugeri que lêssemos o texto de Newton Moreno. A princípio interessou-nos pelo caráter narrativo e pelo fato de que sua estrutura de composição estimulava pelo aspecto não dramático, ou melhor, pós-dramático. Poderia ser o caso. Descobrimos que era muito mais. Veio como uma bomba! Explodiu! Era a pedra de toque que necessitávamos. A virada. Novo ciclo.

\section{Aproximações}

Foram oito meses de trabalho. Sistemáticos.

A seriedade com que nos apoderamos dos diferentes temas contidos no texto e as longas discussões sobre eles serviram para objetivar nosso empenho e para nos debruçamos nele como sendo o projeto a ser levado a cabo.

Primeira etapa, longas sessões de leituras e análises. Platão foi pontual. As imitações e as 
narrações e suas variações e significados. A construção do caráter.

Levantamentos de material interno da peça que pudesse servir para ampliar o seu universo e não reduzi-lo. Como não reduzi-lo a instância folclórica? Existia esse perigo, pois o texto é o tempo todo armado de ciladas, de regionalismos em sua construção, que uma vez não observados em sua sutileza poética para a construção de sonoridade e força dramática podem despencar para o outro lado. Simplório. Canhestro.

Os grandes contadores que conheci eram elegantes no seu desempenho, nobres na ação e generosos nos atos. Pródigos no tratamento e simples na exposição. Aí aparece a humanidade. Como diz Heiner Muller "precisamos arrancar do ser humano o ser humano". Não aquele idealizado. O material de Newton Moreno nos estimulava a cada passo. Não poderia, porém, fugir dos objetivos determinados no sentido da investigação do ATOR NARRADOR. ráveis.

Tive grandes modelos. Retóricos irrepa-

Foram anos de aprendizado atrás do balcão do armazém de meu pai, numa pequenina cidade do interior de São Paulo, do Brasil, do mundo, ouvindo estórias e histórias contadas por caboclos e caipiras, sitiantes e coronéis, gente simples que fez e manteve o imaginário de gerações. Tudo isso acompanhado de tilintar de copos, bater de garfos em pratos fundos que eram limpos pelo apetite voraz, como que lavados no saciar da fome, enquanto aguardavam ser preparadas as compras de suprimentos do mês para manter a família. Cada final de semana eram colônias inteiras, como eram chamadas, que vinham das roças acompanhadas dos administradores para se abastecerem. Eles, os abastecedores das cidades. Como traduzir isso? Nesse singelo espaço mora a origem de tudo. O mais puro teatro. Puro. Uma noção de cidadania que se forjava pelo cumprimento social dos diferentes papéis que se defrontavam e onde o estar ali, embora por relaçôes comerciais e por alguns momentos, fazia sumir todos os contras- tes e aparecer o interesse humano pelo outro e suas estórias. Era um tempo em que a soberania ainda era a do rádio, e em que mesmo este era estimulante para aglutinar pessoas e estimular as relaçôes sociais. O imaginário deu vazão e as comportas da lucidez permitiram aflorar uma percepção de outra ordem. A da criação.

Ensaiávamos em São Paulo, na região do centro. Era impossível não ter a sonoridade da cidade o tempo todo na cabeça e isso colocava uma questão: como fazer para que o espectador, que sai desse ambiente urbano, entre, aceite e respeite o tempo exigido pela realidade narrativa da cena?

Essa é realmente uma grande questão para se pensar na cena contemporânea. Que tratamento dar para esse rito de passagem? E à idéia de sua tragicidade? Os grandes centros urbanos vivem a ausência sistematizada de uma convivência planejada. O progresso. Econômico e não social. Como compor esse outro tempo poético, principalmente dentro de tal realidade? Os veículos de comunicação contemporâneos eliminam a memória desse tempo, que passamos a chamar de "sutil". Da escuta interna. Do ouvir e refletir sobre o outro, com o outro e sobre si mesmo. Porém, o elemento principal continua nos dois universos: a ignorância sobre os direitos humanos e sociais. Tabus e preconceitos ainda ocupam os escaninhos da conveniência da ordem e da invasão da privacidade. O público e o privado na sociedade do espetáculo.

Começamos então a experimentar diferentes tipos de leitura. Um ator lia. O outro ouvia. Invertíamos os papéis. Mudanças de dinâmicas. Reinterpretação. Chegamos à idéia da desconstrução. De tudo! Era necessário desconstruir ao mesmo tempo o espaço e o tempo da realidade para construirmos um novo, ou seja, o da realidade da cena. Ela se explicaria. Chegávamos à magnificência da realidade poética $\mathrm{da}$ cena. A cena diria. Para isso deveríamos nos deixar levar para buscar o que era isso. E descobrir. O tempo mítico da estória no contraponto da história. 
Dessa forma descobrimos que o texto de abertura é dividido em três grandes blocos, cada um com características muito próprias. Eles exigiam tratamento diferenciado. Pensamos então no quanto a música poderia ajudar. Voltamos ao princípio de tudo. A música como estímulo para induzir a teatralidade da oralidade, da redescoberta do sentido e da força das palavras.

Busquei uma música que pudesse dar esse primeiro ponta-pé e empurrar-nos nessa viagem, nos amaciando para a coragem de nos despirmos completamente de nossos esquemas prédeterminados. Começamos de algum ponto. Com essa experiência descobrimos como o texto possibilitava tantas opções que eram até então inimagináveis. Eram longos ensaios de puro exercício retórico. Construções sonoras. Beleza. Entretanto, via de regra, resultavam por demais românticos. Precisávamos dar um passo a mais. Parecia muito simplório. E o contador, aquele anunciado acima, é tudo menos simplório. É objetivo. Sabe onde e como conduzir a narrativa. Essa é a palavra mágica. É de sua responsabilidade criar todo o ambiente para favorecer o golpe, ou os golpes, necessário para seu perfeito relato. Por uns tempos insistindo nisso, chegamos à clareza da importância do rigor técnico, da articulação, da projeção, mas com o autocontrole para não nos deixarmos levar pela falha trágica do esquecimento de que aquilo que estava se processando não poderia e não deveria ser ultrapassado. Encantar pela clareza das idéias.

O narrador é o oficiante. Celebrante. Mágico. Chegamos à conclusão de que faltava certa densidade, gravidade. Isso impunha nova etapa.

Propus então uma mudança no gênero musical. Foi surpreendente! Era uma peça composta para celebração de funerais. As narrativas ganharam em densidade. As imagens começaram a aparecer e a estimular uma reflexão interior. A idéia de cânon foi dando passos mais firmes e ajudando a construir imagens puras. Limpas. Claras. O exercício passou a ser o de improvisar com o texto, reconstruindo e redimensionando seu sentido pela justaposição, sobreposição, repetição, construindo uma espé- cie de mantra, e com isso induzindo o espectador a um sentido ritual.

Durante esse período um dos atores teve de se afastar dos ensaios por questóes de ordem pessoal e, assim sendo, permanecemos no nosso caminho. Para evitar a cristalização do que tínhamos descoberto propus, então, mudarmos novamente o gênero sonoro. Foi surpreendente. Passamos a usar um compositor contemporâneo que revisitou cançôes populares de seu país e estávamos encantados com essa nova possibilidade, pois se de um lado tinha a sonoridade popular que se aproximava muito de nossa realidade, AGRESTE, a modernidade do tratamento provocava estranhamentos, cortes que eram muito intrigantes e que seccionavam o texto de forma surpreendente. Um trabalho minucioso de minutagens para melhor aproveitamento e entrosamento das duas linguagens, verbal e musical, criando outra partitura. Aqui se concretizou a necessidade de pensar em composição. Partitura.

Quando o outro ator voltou, fomos mostrar o resultado do trabalho e quando terminou, sem solenidades, ele disparou: — "Não gosto! Resulta muito melodramático".

Isso, que poderia ser visto como um aspecto negativo, passou a ser considerado como algo importantíssimo. O melodrama que está em nossa tradição poderia, uma vez consciente, ser utilizado a nosso favor. A idéia de radiofonização poderia ser uma possibilidade para fazer a ponte entre o universo simples da peça e o espectador contemporâneo. Pois se tratava de um recurso moderno, ligado à nossa tradição, mas usado sem reforçar nenhuma das partes, só para esclarecê-las. Uma linguagem para ser usada como aproximação de realidades de tempos e espaços muito diferentes. Porém precisávamos de outra música. Aquela era muito cifrada. Do mesmo jeito que as anteriores, uma muito datada dos anos 70 e a outra muito protestante, a última, embora contemporânea era, para o caso da cena, ainda muito folclórica. Os três aspectos eram importantes, mas não poderiam ser percebidos pelo espectador. Ele deveria ser esti- 
mulado a formular imagens, exercitar o imaginário sensibilizado para o reencontro com a tradição oral pela poesia provocada pelas palavras. Aqui chegávamos no ponto fundamental da proposta. Longos meses. Longas horas. Intermináveis tentativas no sentido de resgatar a poesia da mais comum das linguagens. A oralidade. Nisso estávamos presos à tradição. Ao contador de história. À infância de nossa cultura. À simplicidade de se fazer reconhecer pelo contado. E pela admissão de nossa ignorância diante do não aprendizado de tão alto conhecimento. Nisso estávamos ligados ao trágico. A passagem do relato para a aparição do fantasma reencarnado dos heróis é uma odisséia cultural. Ter a coragem de assumir-se personagem implica em reconhecimentos de valores e sentidos e sentimentos que são muito complexos. O embate provocado pelo jogo narrado e mostrado aos espectadores ganha caráter nobre pela importância do valor retórico. Discute-se e apresenta-se o homem em todas as suas contradições. $\mathrm{O}$ épico ganha consistência como narrativa e exposição de contrastes e contradições sociais. Das contradições representadas pelas idéias como das representadas pelo julgamento estimulado no espectador diante dos fatos apresentados. A objetividade retórica reforça o embate do espectador diante do mundo representado e a subjetividade ganha toda a sua concretude poética pela cena narrada.

Incontinenti, estimulamos os atores a que experimentassem com outra música. A que é usada hoje no espetáculo. O resultado foi o que buscávamos! Logo nos primeiros acordes fomos os três tomados por aquela percepção fina de quem sabe o caminho a percorrer e se lança ao seu encontro. Havíamos chegado, depois de tanto, ao primeiro tempo de nossa investigação. Quatro versōes. Era nosso primeiro material reconhecível como proposta objetiva para a cena que buscávamos. Agora tínhamos o primeiro bloco do texto. Denominamos tempo mítico, pois evoca uma lembrança a ser reconstruída no imaginário, o causo de amor. E morte.
O segundo bloco é remontado, sobreposto três vezes. É o tempo do acontecido. O tempo da relembrança do acontecimento, do fato. E o tempo da urgência do acontecimento, do esclarecimento e suas decisões.

Não existe psicologia. Existe uma mudança rítmica e melódica na fala limpa, cadenciando a respiração e alterando o estado do espectador pela construção de ritmos alternados em que, ávido por acompanhar o causo, ele é colocado em outro estado. Ativo.

Aqui aparecem as primeiras garatujas, nas repetições do que teriam sido: o riso dele ao vêla, a felicidade dela, o êxtase, a apresentação da sonoridade da fala folclórica dos conversadores.

$\mathrm{O}$ primeiro movimento. Girar a cabeça para conversar com o outro.

"- Chegaria no mar de tanto passo.

- Chegaria se tivesse corrido esse tanto de chão pro outro lado."

E a complementação do pensamento de um no outro. São dois. São um. Surgimento do estado de consciência, e a tomada de decisão. Voltar ou continuar o caminho da opção feita.

Terceiro bloco. A dúvida! A música retoma o diálogo com o tempo suspenso, o tempo imemorial da fome e do cansaço. Do abandono. Da lezera. Da perda dos sentidos. Do aconchego no outro.

"-Deitaram os corpos na sombra de um mandacaru. Na margem do que fora um riacho."

A alucinação, visões. O encontro com outra realidade. A explosão da vida. E morte.

\section{Joseph Beuys - Materiais e matérias}

Chegamos finalmente à idéia de construção das esculturas sonoras, segundo Beuys.

Alain Borer, estudioso de Beuys, nos diz, em "A pedagogia criativa de Joseph Beuys contra o 'silêncio de Marcel Duchamp": "Enquanto a palavra 'escultura' em seu sentido clássico designa um objeto tridimensional, os ensinamentos de Beuys ou entrevistas já representam a obra: a fala é escultura. A voz (o seu volume, 
sua plasticidade, seus tons) participa do espaço criado, (in)forma-o como um lugar de intercâmbio, um lugar de instantânea renovação. (...) Em seu caráter imediato, a voz, e nesse sentido Bueys esculpiu muito, opõe-se à eternidade do mármore; mas, sendo flutuante, efêmera e também confusa, ela aponta ao mesmo tempo para uma 'obra' coletiva ainda por vir, no longo caminho que ela ensina."

Beuys passou a ser referência obrigatória e ele está o tempo todo referenciado dentro do espetáculo, desde as suas idéias até ser concretamente usado, como projeção da obra. Ele recomenda: "o mais elementar dos relacionamentos com um objeto".

“(...) ele não expõe os seus elementos como 'obras' (de arte): a matéria 'em estado bruto' constitui em primeiro lugar um espaço pedagógico, ela oferece matéria para a reflexão: ela não é exposta por si mesma, mas servindo a um processo de transformação - um primeiro lugar."

Nisso vimos um grande aprendizado. A questão não é meramente retórica, mas de uma retórica que enseja a poesia. Outra pedagogia. Principalmente para a idéia de cena.

São matérias que se reorganizam e recriam poeticamente novos diálogos internamente. A espetacularidade está na construção e desconstrução de realidades processuais/virtuais, situações construídas fornecendo matéria para servir como objeto exposto, para refletir sobre o processo de destruição e morte da realidade social que representam. Lembremos da visão de Bueys sobre a Cabeça de touro, de Picasso, que propunha pensar sobre a tourada, onde está em jogo a morte ritual. E a saúde. $\mathrm{O}$ espaço riscado graficamente como denúncia da ausência do corpo representado pela ossada. O extermínio. O grafismo policial sobre a ausência do corpo exterminado.

E principalmente a máxima: "como reduzir o abismo que separa a cidade moderna do estado de natureza”. Essa era nossa verdadeira questão: como lidar, tratar material tão complexo e simples.
A construção poética dos outros movimentos parte da consideração de que os materiais são a força da cena. O tecido cobre, veste, e dialeticamente desvela a realidade. Descortinase o tempo todo nova realidade na ação.

O som da fala, e sua idéia de representação, assim como o fogo, leva pelo ar a combustão, instaurando nova poesia cênica. Pensemos na construção imagética instaurada pelas palavras, assim como o fogo da lamparina que destrói a casa. O feltro, objeto a princípio não correspondente ao ideal para uma representação realista, dada a realidade geográfica do agreste, protege os corpos plasticamente e passa a ser aceito poeticamente como tal, dado que nos ambientes urbanos o material é reconhecidamente usado pelos pobres como protetor do frio. Entretanto, está talhado como terno, símbolo de elegância social do mundo masculino.

Assim, também, a lamparina em combustão, elemento primitivo, revela a intimidade com a ação poética do espaço explorado e devastado pela ignorância. A construção temática do fogo como elemento e como argumento poético configura-se como material primário da dramaturgia da cena. Nele está centrado o ponto mítico a ser desenvolvido: o seu sentido retórico.

\section{O espaço do imaginário e da consciência como espaço da ação como representação}

Primeira regra: aceitar o jogo proposto e não propor um jogo. Entender e recriar essa realidade, e não inventar uma realidade. Fazer, realizar essa ação de forma que ela instigue a reflexão. Aqui começa a se reorganizar um sentido do fazer teatral. Acreditar que o material fornecido pelo autor é enunciado e que sua poesia deverá ser processada cenicamente. Outra idéia de poesia. Faz parte disso o espectador. Nisso é que ficamos rebatendo a primeira etapa do trabalho para avançarmos e descobrirmos as outras. Saber qual ou quais as regras que seriam determinantes para a construção das jogadas a serem realizadas. 
Voltamos a Beuys, naquilo que ele chamava de "escultura social", ou seja, o dominio ampliado, propagar socialmente as idéias. Como que insinuando as possibilidades a serem provocadas.

Assim sendo, quando o espectador entra na sala temos uma instalação de realidade criada com vários elementos. Tudo é reconhecível. Aguardando tratamento. Tradução. A cena se expande pela luz, pelo som mântrico, induzindo ao estado de participação. Nada às escondidas. Luz preparada, mas clara. No espaço da cena a ser representada, estante de metal com objetos, atores, paralelepípedos, roupas (de feltro), microfones, projetor. Eis o ambiente.

Primeira ação. Vestir-se para representar. Cumprimentos. Cordialidade. Instalação. Terceiro sinal.

Espaço separado por paralelepípedos. Som. Voz. Escuro. Imagens provocadas pela sonoridade. A criação pelo imaginário. $\mathrm{O}$ espectador em ação. $\mathrm{O}$ imaginário representando. $\mathrm{O}$ ator narrando.

\section{Os três tempos}

A construção do espetáculo pelo espectador. A máxima de Baudelaire citado de memória: No espaço vazio, nada. $\mathrm{O}$ espaço vazio, que tem um aparador, que tem um caramujo, que ao ser colocado no ouvido nos leva ao infinito do mar, em ondas e movimentos...
Como não lembrar de Szondi: "O processo épico, a própria narrativa, apresenta-se assim como ação dramática”.

Tudo é narrado. A cena narra. Outros recursos aparecem. Transmutam-se valores. Aparecem novos significados. Em suma, constróise outra cena. Ela é reflexiva.

Voltando-se a Szondi: "O presente da representação é como que mais largo que o da ação; por isso, o olhar fica atento não apenas ao desfecho, mas também ao andamento e ao que passou. No lugar da direção dramática com objetivos definidos entra a liberdade épica de demorar-se e repensar. Visto que o homem agente não é mais que objeto do teatro, é possível ir além e perguntar sobre os motivos da ação".

Constrói-se outra realidade, espaço mambembe, que arquitetonicamente serve de suporte para a realidade, agreste, a ser narrada. AGRESTE deixa de ser região geográfica característica e passa a ser também adjetivo.

São narradores, e a partir de então vão atuar e refletir sobre as açôes. Criticam, apresentam possibilidades de outro olhar sobre os atos mostrados.

A vida reconstruída em outro lugar - no imaginário - deu lugar a fatos que levam a agir sobre a realidade. Deu-se o fenômeno do teatro.

A casa se incendeia e tragicamente somos observadores da tragédia da exclusão pelo preconceito e pela ignorância de seres humanos.

Os narradores voltam aos seus lugares. Cumprimentam-se. A cordialidade e o sorriso cúmplice fecham o ato. 